\title{
Biochemical Characterization of Alkaliphilic Cyclodextran Glucanotransferase from an Alkaliphilic Bacterium, Paenibacillus daejeonensis
}

\author{
So-Jin Yang ${ }^{1 \dagger}$, Jin-A $\mathrm{Ko}^{2 \dagger}$, Hae-Soo Kim ${ }^{1}$, Min-Ho Jo ${ }^{1}$, Ha-Nul Lee ${ }^{1}$, Bo-Ram Park ${ }^{3}$, and Young-Min Kim ${ }^{1 *}$ \\ ${ }^{1}$ Department of Food Science and Technology and BK21 Plus Program, Chonnam National University, Gwangju 61186, Republic of Korea \\ ${ }^{2}$ Radiation Breeding Research Center, Advanced Radiation Technology Institute, Korea Atomic Energy Research Institute, Jeongeup, Republic \\ of Korea \\ ${ }^{3}$ Department of Agrofood Resources National Academy of Agricultural Science, RDA
}

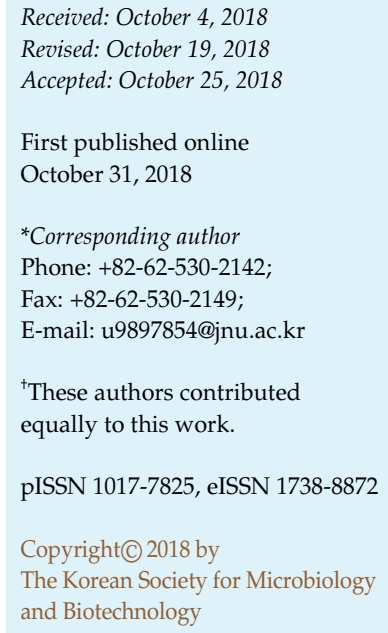

Cycloisomaltooligosaccharide glucanotransferase (CITase) was isolated from alkaliphilic Paenibacillus daejeonensis via an amino acid homology search for the reported CITase. The recombinant alkaliphilic CITase (PDCITase) from $P$. daejeonensis was expressed in an Escherichia coli expression system and purified as a single protein band of $111 \mathrm{kDa}$. PDCITase showed optimum activity at $\mathrm{pH} 8.0$ and retained $100 \%$ of activity within a broad $\mathrm{pH}$ range (7.0-11.5) after $18 \mathrm{~h}$, indicating alkaliphilic or alkalistable CITase properties. In addition, PDCITase produced CI-7 to CI-17, CI-18, and CI-19, which are relatively large cycloisomaltooligosaccharides yet to be reported. Therefore, these large cycloisomaltooligosaccharides can be applied to the improvement of water solubility of pharmaceutical biomaterials.

Keywords: Cyclodextran, cycloisomaltooligosaccharide glucanotransferase, Paenibacillus daejeonensis, glycoside hydrolase family 66

\section{Introduction}

Cycloisomaltooligosaccharide (CI), also known as cyclodextran, is a cyclic oligosaccharide with a glucose moiety similar to that of cyclodextrin (CD), a cyclic $\alpha-1,4$ oligosaccharide whereas CIs are linked by $\alpha-1,6$-glucosidic bonds. CIs consist of 7-17 glucose units (CI-7 to CI-17) of $\alpha-1,6$-linked glucose [1-3]. CIs are produced from dextran via intramolecular transglucosylation catalyzed by cycloisomaltooligosaccharide glucanotransferase (CITase; E.C. 2.4.1.248). CIs, especially small ones, CI-7 to CI-9, strongly inhibit glucansucrase activity in mutant streptococci [4], suggesting that CIs can be employed for the prevention of dental caries. Furthermore, CIs have 100-fold higher solubility in aqueous solutions than CDs do. Due to the structural nature of the $\alpha-1,6$ linkage, it has a wider molecular diameter than that of the $\alpha-1,4$ linkage, and a CI can encapsulate a guest molecule [2]. Therefore, CIs have attracted attention as potential solubilization reagents for functional materials that cannot be encapsulated by CDs. Among the reported CIs, relatively large cycloisomaltodecaose (CI-10) has a remarkable inclusion ability as compared with CDs and other CIs, and they have shown high stability according to Victoria blue B staining [2]. Thus, CIs may serve as a novel encapsulation agent for water-insoluble pharmaceutical biomaterials.

To date, three CI-producing bacteria, Paenibacillus agaridevorans T-3040 (formerly Bacillus circulans T-3040; CITase-T3040), Paenibacillus sp. 598K (CITase-598K), and B. circulans U-155 (CITase-U155), have been reported [1, 3, 5-7]. CITase catalyzes intramolecular transglucosylation of dextran [6]. Furthermore, the three reported enzymes have optimal pH around 6.0 and produce CI-7 to CI-17 [3]. Recently, B. agaridevorans T-3040 and Paenibacillus sp. 598K were shown to also produce CIs synergistically by means of 6- $\alpha$-glucosyltransferase (6-GT) and CITase from starch 
$[5,8,9]$. In particular, 6-GT catalyzes a reaction forming long isomaltooligosaccharides ( $\alpha$-1,6-glucosidic linkage from starch) and maltooligosaccharides ( $\alpha$-1,4-glucosidic linkage) with CITase and continually generates CIs from the produced isomaltooligosaccharides [9]. Thus, CIs are produced from various substrates such as dextran and $\alpha-1,6$ glucan by CITase, and from starch and $\alpha-1,4$ glucan via cocatalysis by $6-\mathrm{GT}$ and CITase.

Although some CITases have been previously reported, various studies are needed to characterize and improve the function of these enzymes from bacterial sources. Recently, we discovered that an alkaliphilic bacterium, Paenibacillus daejeonensis, has a gene encoding a CITase-like enzyme according to the amino acid similarity with the CITase from B. agaridevorans T-3040 [9]. Besides, CIs were confirmed to be present in dextran-containing culture broth of $P$. daejeonensis [9].

Therefore, the purpose of this study was to describe the cloning and characterization of one of the putative CITase genes, pdcit, belonging to glycoside hydrolase family 66 from $P$. daejeonensis. The novel alkaliphilic CITase from $P$. daejeonensis was found to produce large CIs via high catalytic activity in a higher $\mathrm{pH}$ range relative to other CITases.

\section{Materials and Methods}

\section{Materials}

Standard CIs such as CI-7, CI-8, and CI-9 were kindly provided by Professor Funane Kazumi at Yamanashi University in Japan. Escherichia coli DH5 $\alpha$ and E. coli Rosetta (DE3) cells were used for cloning and overexpression of the recombinant enzyme, respectively. They were aerobically grown at $37^{\circ} \mathrm{C}$ in Luria-Bertani (LB) broth or on LB agar plates.

\section{Cloning of Putative cit Genes from P. daejeonensis}

The genomic DNA of P. daejeonensis (No. 3745, Korea Collection for Type Cultures, South Korea) was extracted using the genomic DNA extraction kit. A PDCITase-coding gene, pdcit, of $P$. daejeonensis was amplified by polymerase chain reaction by means of Pfu DNA polymerase (Enzynomics, South Korea) with genomic DNA and a primer pair (forward primer, $5^{\prime}$-AGCCATATGGCTAGC ATGGCAATCCAAAAGAAAGCC-3' and reverse primer, 5'-TGC GGCCGCAAGCTTTCAATCTATTTCAATTTCAAAATCCG-3') containing NheI and HindIII sites (italicized), respectively. The amplified gene was digested with NheI and HindIII and was inserted at the corresponding sites of pET28a(+) (Novagen, USA) encoding a C-terminal His-tag. DNA sequencing analysis was performed by Solgent Inc. (South Korea). Purified pET28a-pdcit was then transfected into E. coli Rosetta (DE3) for protein expression.

\section{Expression and Purification of Recombinant CITase}

E. coli Rosetta (DE3) carrying the constructed plasmid, pET28apdcit, was grown in LB broth containing $50 \mu \mathrm{g} / \mathrm{ml}$ kanamycin at $37^{\circ} \mathrm{C}$ to absorbance of 0.5 at $600 \mathrm{~nm}$, and the recombinant PDCITase was induced with $0.1 \mathrm{mM}$ isopropyl $\beta$-D-thiogalactopyranoside for $21 \mathrm{~h}$ at $18^{\circ} \mathrm{C}$. After the cells were collected by centrifugation at $10,000 \times g$, they were resuspended in $20 \mathrm{mM}$ sodium phosphate buffer ( $\mathrm{pH} 7.4$ ) containing $0.5 \mathrm{M} \mathrm{NaCl}$ (buffer A). The resuspended cells were sonicated and centrifuged at $12,000 \times g$ for $30 \mathrm{~min}$ at $4^{\circ} \mathrm{C}$, and the supernatant was loaded on a $\mathrm{Ni}^{2+}$-chelating Sepharose column equilibrated with buffer A. The column was washed with buffer A containing $5 \mathrm{mM}$ imidazole, and the sample protein was eluted with buffer A containing $200 \mathrm{mM}$ imidazole. The protein was concentrated using an Amicon Ultra with molecular weight cutoff 5,000 (Millipore, Billerica, USA). Protein concentration was determined by absorbance at $280 \mathrm{~nm}$ during purification and was measured by the Bradford method [10].

\section{An Enzyme Assay}

An enzyme solution was added to $2 \%(\mathrm{w} / \mathrm{v})$ dextran T2000 (molecular weight 200,000) in $40 \mathrm{mM}$ Britton-Robinson buffer ( $\mathrm{pH}$ 8.0). The reaction mixtures were incubated at $30^{\circ} \mathrm{C}$ for $2 \mathrm{~h}$, and the reactions were stopped by boiling for $10 \mathrm{~min}$. To each mixture, $100 \mathrm{mU}$ of Streptococcus mutans dextran glucosidase (DexB) [11] and Bacteroides thetaiotaomicron $\alpha$-glucosidase (SusB) [12] in $40 \mathrm{mM}$ Na-acetate buffer ( $\mathrm{pH}$ 6.0) were added to digest linear oligosaccharides to glucose at $37^{\circ} \mathrm{C}$ for $6 \mathrm{~h}$. The reactions were stopped by boiling for $10 \mathrm{~min}$, and each sample was mixed with an equal volume of acetonitrile. CITase activity was determined by measuring the amounts of CIs [the sum of the amounts of CI-7, CI-8, and CI-9 produced from $2 \%(\mathrm{w} / \mathrm{v})$ dextran T2000] by HPLC on a TSK gel Amide- 80 column $(4.6 \times 250 \mathrm{~mm}$; Tosoh, Japan) [3]. The mobile phase was acetonitrile-water $(55: 45(\mathrm{v} / \mathrm{v}))$, and the flow rate was $1 \mathrm{ml} / \mathrm{min}$. CIs were detected with a Refractive Index Detector (RID-20A, Shimadzu, Japan). One unit of CITase activity was defined as the amount of the enzyme producing $1 \mu \mathrm{mol}$ of CIs (the sum of CI-7, CI-8, and CI-9) per minute [3].

\section{Biochemical Characterization of CITase}

To determine the effect of $\mathrm{pH}$, PDCITase was incubated at $30^{\circ} \mathrm{C}$ in $100 \mathrm{mM}$ Britton-Robinson buffer ( $\mathrm{pH} 3.0-11.0)$ [13] with $2 \%$ $(\mathrm{w} / \mathrm{v})$ dextran T2000. For determination of $\mathrm{pH}$ stability, the enzyme was kept at $4^{\circ} \mathrm{C}$ for $18 \mathrm{~h}$ in $100 \mathrm{mM}$ Britton-Robinson buffer ( $\mathrm{pH}$ 2.0-11.5), and the residual PDCITase activity was examined. To determine optimal temperature, the enzyme was incubated at $15-60^{\circ} \mathrm{C}$ for $1 \mathrm{~h}$ in $40 \mathrm{mM}$ Britton-Robinson buffer ( $\mathrm{pH} 8.0)$ with $2 \%(\mathrm{w} / \mathrm{v})$ dextran T2000. For evaluation of thermal stability, the enzyme was kept at $20-60^{\circ} \mathrm{C}$ for $18 \mathrm{~h}$ in $40 \mathrm{mM}$ Britton-Robinson buffer ( $\mathrm{pH} 8.0$ ), and the residual enzymatic activity was examined at $30^{\circ} \mathrm{C}$. For determining the effects of various cations on the reaction velocity of PDCITase, reactions were carried out in the presence of each cation $(10 \mathrm{mM})$ at optimal $\mathrm{pH}$ and temperature. To determine kinetic constants, the initial 
velocity $(v)$ was measured by means of various concentrations (20, $32,40,60,80,160,240,320$, and $400 \mu \mathrm{M})$ of dextran $\mathrm{T} 2000$ in $40 \mathrm{mM}$ Britton-Robinson buffer ( $\mathrm{pH} 8.0$ ) at $30^{\circ} \mathrm{C}$.

\section{Product Analysis}

Ethanol $66 \%(\mathrm{v} / \mathrm{v})$ was added to the PDCITase reaction mixture to remove the dextran. After precipitation, the remaining dextran was hydrolyzed to isomaltooligosaccharides to form glucose by DexB [11] and SusB $[12,14]$. The reaction mixture was next treated with $2 \mathrm{M} \mathrm{NaOH}$ at $100^{\circ} \mathrm{C}$ for $30 \mathrm{~min}$ to remove the reducing sugar. After the reaction products were passed through Amberlite MB3 (Merck, Germany) to remove ionic impurities, the reaction products were concentrated in a vacuum evaporator (EYELA, Japan) for further analysis. The molecular weight of products was analyzed by matrix-assisted laser desorption/ionization tandem time-of-flight (MALDI-TOF/TOF) mass spectrometry (MS) on an ABI 4800 Plus TOF-TOF mass spectrometer (Applied Biosystems, USA). A sample was dissolved in $2.5 \mu \mathrm{l}$ of the sample solution [ $50 \%(\mathrm{v} / \mathrm{v})$ acetonitrile with $0.1 \%(\mathrm{v} / \mathrm{v})$ trifluoroacetic acid], and $1 \mu \mathrm{l}$ of the sample was dissolved in the matrix [0.06 g $\alpha$-cyano-4hydroxycinnamic acid, $50 \%(\mathrm{v} / \mathrm{v})$ acetonitrile with $0.1 \%(\mathrm{v} / \mathrm{v})$ trifluoroacetic acid] [15].

\section{Results and Discussion}

\section{Gene Cloning, Expression, and Purification of CITase (PDCITase) from $P$. daejeonensis}

The gene was found to be $2,898 \mathrm{bp}$ long and to encode a putative CITase from the alkaliphilic bacterium $P$. daejeonensis with the same sequence as that reported in NCBI (Accession No. WP_020619177) and was expressed in E.coli. The primary structure of PDCITase turned out to share high sequence identity, $65 \%, 69 \%$, and $89 \%$, with CITase-T3040, CITase-U155, and CITase-598K, respectively [1, 3, 5-7], all of which belong to the glycoside hydrolase family 66 [16]. The recombinant enzyme was purified, with a final purification yield of $9.4 \%$ and specific activity of $42 \mathrm{mU} / \mathrm{mg}$. Overall, $6.4 \mathrm{mg}$ of active protein was obtained from $1.5 \mathrm{~L}$ of culture broth. The final purified enzyme yielded a single band with a molecular mass of approximately $111 \mathrm{kDa}$ in

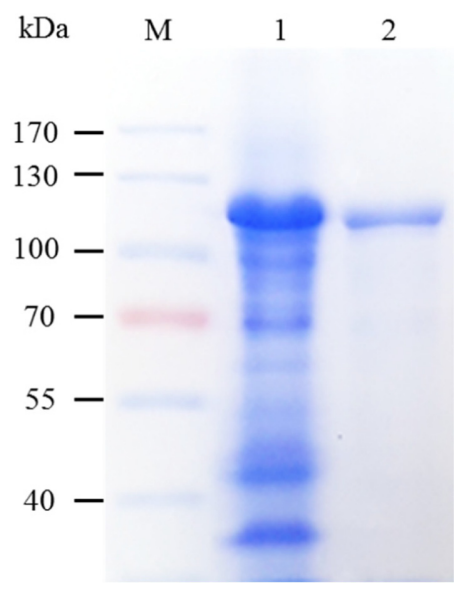

Fig. 1. Purification of recombinant PDCITase.

SDS-PAGE of purified proteins in an $8 \%(\mathrm{w} / \mathrm{v})$ gel. Purified proteins $(12 \mu \mathrm{g})$ were loaded onto a polyacrylamide gel, separated by electrophoresis, and visualized with Coomassie Brilliant blue staining. Lane M, size markers; lane 1, PDCITase cell-free extract; lane 2, purified PDCITase.

sodium dodecyl sulfate polyacrylamide gel electrophoresis (SDS-PAGE) analysis (Fig. 1), in agreement with the calculated value of 107,809 Da based on the amino acid sequence plus six histidine residues at the carboxy terminus.

\section{Effects of Temperature and $\mathrm{pH}$ on Activity and Stability}

The purified PDCITase was examined for temperature and $\mathrm{pH}$ effects. PDCITase had optimum temperature at $45^{\circ} \mathrm{C}$ and retained $80 \%$ of activity at $40^{\circ} \mathrm{C}$ after $18 \mathrm{~h}$. The observed thermal stability at $40^{\circ} \mathrm{C}$ was the same as or somewhat lower compared with CITase-T3040 at $40^{\circ} \mathrm{C}$, CITase-598K at $50^{\circ} \mathrm{C}$, or CITase-U155 at $50^{\circ} \mathrm{C}$ (Figs. $2 \mathrm{~A}$ and $2 \mathrm{~B})$. The optimum $\mathrm{pH}$ for PDCITase activity was found to be 8.0, and the enzyme was stable across a broad $\mathrm{pH}$ range (7.0-11.5) after incubation at $4^{\circ} \mathrm{C}$ for $18 \mathrm{~h}$ (Fig. 2C). The optimum $\mathrm{pH}$ is comparable to that of CITase-598K (pH 5.5-8.0) and CITase-T3040 (pH 5.5-8.0). CITase-598K is $10^{\circ} \mathrm{C}$ more thermally stable $\left(\leq 50^{\circ} \mathrm{C}\right)$ than PDCITase or

Table 1. A comparison of enzymatic properties of CITases from B. circulans U155, P. sp. 598K, B. circulans T-3040, and P. daejeonensis.

\begin{tabular}{|c|c|c|c|c|}
\hline Property & CITase-U155 & CITase-598K & CITase-T3040 & PDCITase \\
\hline DP of CI & - & CI-7 to CI-17 & CI-7 to CI-17 & CI-7 to CI-19 \\
\hline Main product & CI-7 & CI-7 & CI-8 & CI-7 \\
\hline Optimum pH & 6.0 & $5.5-8.0$ & $5.5-8.0$ & 8.0 \\
\hline pH stability & - & $5.0-9.0$ & $5.0-9.0$ & $7.0-11.5$ \\
\hline \# of amino acid residues & 934 & 932 & 934 & 965 \\
\hline Reference & 7 & 5 & 2 & This study \\
\hline
\end{tabular}


A

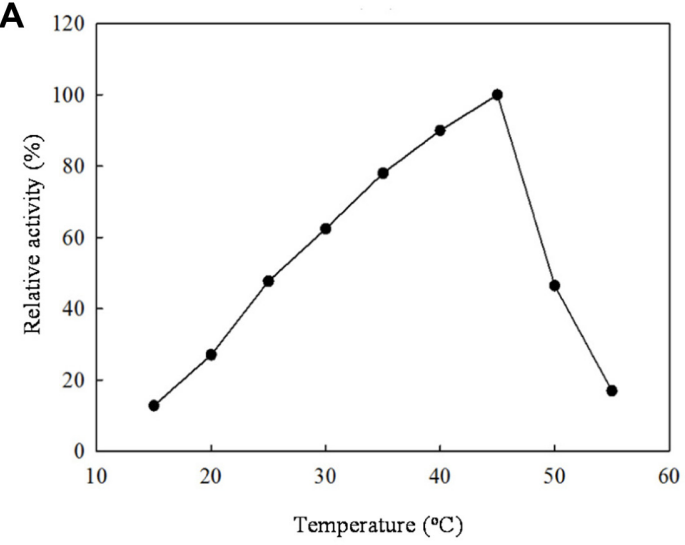

C

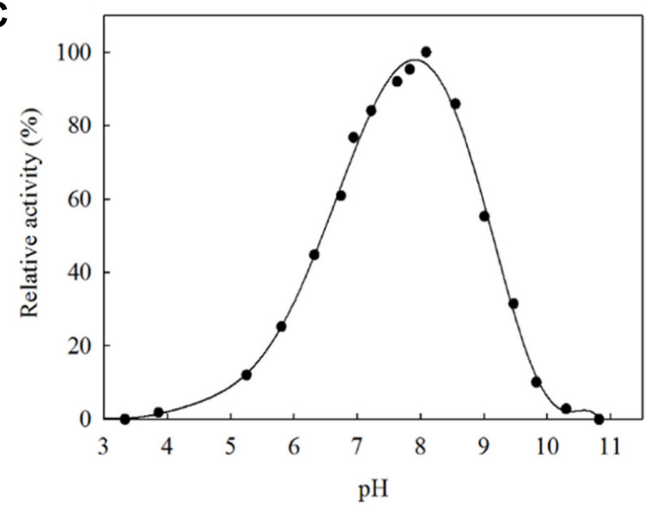

B
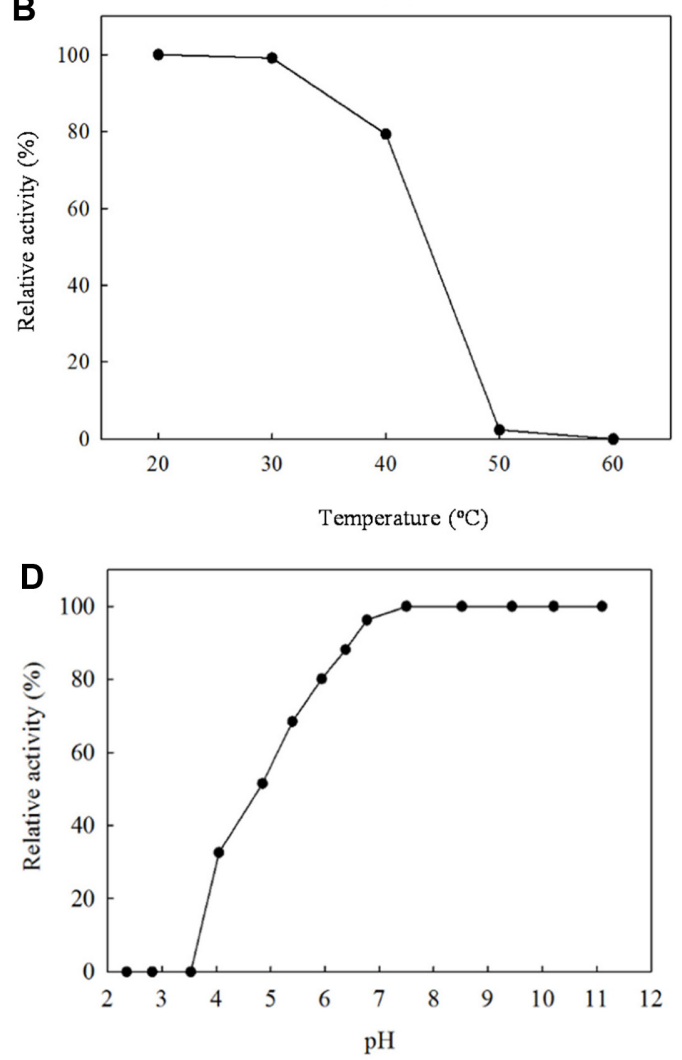

Fig. 2. Optimum temperature, A, thermal stability, B, optimum $\mathrm{pH}$ for activity, $\mathbf{C}$, and $\mathrm{pH}$ stability, $\mathbf{D}$, of PDCITase.

To examine the effect of temperature, PDCITase activity was measured at $15-60^{\circ} \mathrm{C}$ in $40 \mathrm{mM}$ Britton-Robinson buffer ( $\left.\mathrm{pH} 8.0\right)$ with $2 \%$ (w/v) dextran T2000. To evaluate the temperature stability of PDCITase, it was kept at 20-60 ${ }^{\circ} \mathrm{C}$ for $18 \mathrm{~h}$ in $40 \mathrm{mM}$ Britton-Robinson buffer (pH 8.0), and residual enzymatic activity was measured at $30^{\circ} \mathrm{C}$ in $40 \mathrm{mM}$ Britton-Robinson buffer $(\mathrm{pH} 8.0)$ with $2 \%(\mathrm{w} / \mathrm{v})$ dextran T2000. To examine the effect of $\mathrm{pH}$, enzymatic activity was measured at $30^{\circ} \mathrm{C}$ in $40 \mathrm{mM}$ Britton-Robinson buffer ( $\left.\mathrm{pH} 3.0-11.0\right)$ with $2 \%$ (w/v) dextran T2000. To assess the $\mathrm{pH}$ stability of PDCITase, it was kept at $4^{\circ} \mathrm{C}$ for $18 \mathrm{~h}$ in $100 \mathrm{mM}$ Britton-Robinson buffer $\left(\mathrm{pH}\right.$ 2.0-11.5), and residual activity was measured at $30^{\circ} \mathrm{C}$ in $40 \mathrm{mM}$ Britton-Robinson buffer ( $\mathrm{pH} 8.0$ ) with $2 \%\left(\mathrm{w} / \mathrm{v}\right.$ ) dextran T2000. PDCITase was kept at 20-60 ${ }^{\circ} \mathrm{C}$ for $18 \mathrm{~h}$ in $40 \mathrm{mM}$ Britton-Robinson buffer ( $\mathrm{pH}$ 8.0). The residual enzymatic activity was measured at $30^{\circ} \mathrm{C}$ in $40 \mathrm{mM}$ Britton-Robinson buffer ( $\mathrm{pH}$ 8.0) with $2 \%(\mathrm{w} / \mathrm{v})$ dextran T2000.

CITase-T3040 $\left(\leq 40^{\circ} \mathrm{C}\right)$. Nonetheless, the $\mathrm{pH}$ stability of PDCITase ( $\mathrm{pH} 7.0-11.5)$ has a broader range than that of CITase-598K (pH 5.0-9.0) or CITase-T3040 (pH 5.0-9.0) [5]. This feature is likely due to the characteristics of the alkaliphilic parent strains whose growth is stimulated in an alkaline environment from $\mathrm{pH} 8.0$ to 12.0 [17]. Therefore, PDCITase had the higher optimum $\mathrm{pH}$ area than other CITases. This stability in a broad $\mathrm{pH}$ range needs to be further elucidated on the basis of the three-dimensional structure of PDCITase. Additionally, the broad $\mathrm{pH}$ stability of PDCITase and other CITases may be useful in industrial processes involving alkaline conditions.

\section{Effects of Metal Ions on Enzymatic Activity}

CITase-T3040 is activated and stabilized by the presence of $\mathrm{Ca}^{2+}$ owing to a metal-binding site $[18,19]$. Enzymatic activity of PDCITase increased by $107 \%, 117 \%$, and $123 \%$ in the presence of $\mathrm{Mg}^{2+}, \mathrm{K}^{+}$, and $\mathrm{Na}^{+}$, respectively, but there was $74 \%$ and $54 \%$ of residual activity in the presence of $\mathrm{Mn}^{2+}$ and $\mathrm{Co}^{2+}$, respectively. Nonetheless, the activity of the enzyme was strongly inhibited in the presence of such metal ions as $\mathrm{Cu}^{2+}$ (data not shown). PDCITase did not manifest activation by $\mathrm{Ca}^{2+}$ ion addition (activity 98\%) compared to the $130 \%$ increase in the activity of CITaseT3040 by $\mathrm{Ca}^{2+}[18]$. In the three-dimensional structure of CITase-T3040, there are two $\mathrm{Ca}^{2+}$-binding sites in the CBM35 structure. PDCITase contains the same amino acids (e.g., Glu418, Glu420, Thr437, Gly440, and Asp543) as CITase-T3040 does in the highly conserved first $\mathrm{Ca}^{2+}$ binding site [19]. Nevertheless, the second $\mathrm{Ca}^{2+}$-binding 
Table 2. Kinetic parameters of CITases toward dextran.

\begin{tabular}{lcccc}
\hline \multicolumn{1}{c}{ Enzyme } & $K_{\mathrm{m}}(\mathrm{mM})$ & $k_{\text {cat }}\left(\mathrm{s}^{-1}\right)$ & $\begin{array}{c}k_{\text {cat }} / K_{\mathrm{m}} \\
\left(\mathrm{s}^{-1} \cdot \mathrm{mM}^{-1}\right)\end{array}$ & Reference \\
\hline CITase-T3040 & 0.18 & 3.2 & 17.8 & 5 \\
CITase-598K & 0.18 & 5.8 & 32.2 & 5 \\
PDCITase & 0.02 & 1.3 & 67.4 & This study \\
\hline
\end{tabular}

site was found to be not strictly conserved between CITaseT3040 and PDCITase. The lesser effect of $\mathrm{Ca}^{2+}$ on PDCITase suggests that $\mathrm{Ca}^{2+}$ is more tightly bound to CITase-T3040 as compared to PDCITase or CITase-598K [5, 19]. This loose binding of PDCITase or CITase-598K to $\mathrm{Ca}^{2+}$ ions may influence the patterns of production of CIs.

\section{Enzymatic Kinetics of PDCITase}

Kinetic parameters of PDCITase toward dextran T2000
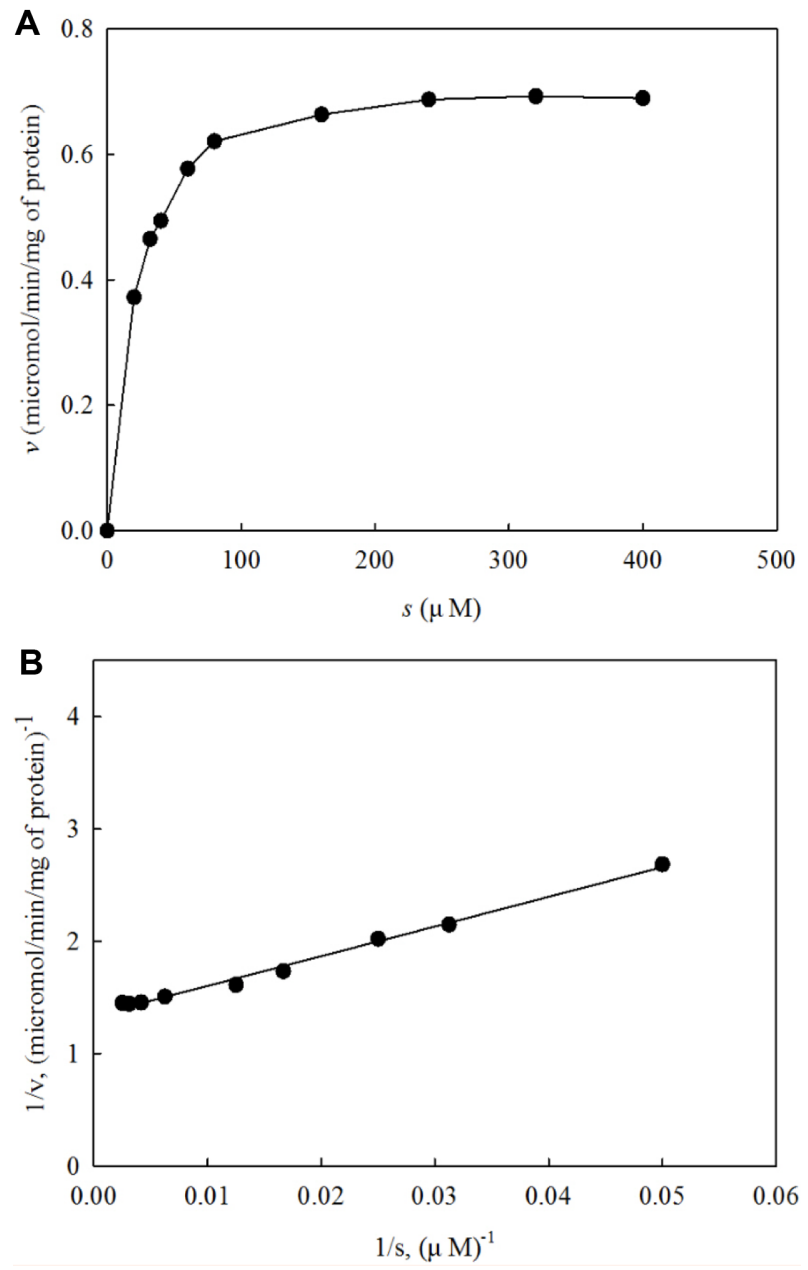

Fig. 3. A Michaelis-Menten plot, A, and a Lineweaver-Burk plot, B, of the PDCITase reaction with dextran T2000. were determined (Table 2 and Fig. 3), and $v$ denotes the rate of production of CIs (the sum of CI-7, CI-8, and CI-9). The enzymes turned out to have similar $k_{\text {cat }}$ values toward dextran (3.2 for CITase-T3040, 5.8 for CITase-598K, and 1.3 for PDCITase), but $K_{\mathrm{m}}$ of PDCITase is 9-fold lower than those of CITase-T3040 and CITase-598K [5]. Therefore, the second-order rate constant, $k_{\text {cat }} / K_{\mathrm{m}}$ of PDCITase $\left(67.4 \mathrm{~s}^{-1} \cdot \mathrm{mM}^{-1}\right)$ is approximately 2.1- and 3.7-fold higher than those of CITase-598K $\left(32.2 \mathrm{~s}^{-1} \cdot \mathrm{mM}^{-1}\right)$ or CITase-T3030 $\left(17.8 \mathrm{~s}^{-1} \cdot \mathrm{mM}^{-1}\right)$, respectively [5].

\section{Production Patterns and Amino Acid Sequence Similarity}

CI-7 to CI-19 were produced by PDCITase, with CI-7 to CI-9 being the main products (Fig. 4), and MALDI-TOF/ TOF MS analysis revealed that PDCITase produces CI-7 to CI-19 (Fig. 5). These CIs are likely to be novel large CIs. This finding points to the necessity of further research on the production and utilization of the high polymerization degree of CI. PDCITase was found to share high primarysequence identity, namely, 66\% with CITase-T3040, 71\% with CITase-U155 (71\%), and 89\% with CITase-598K.
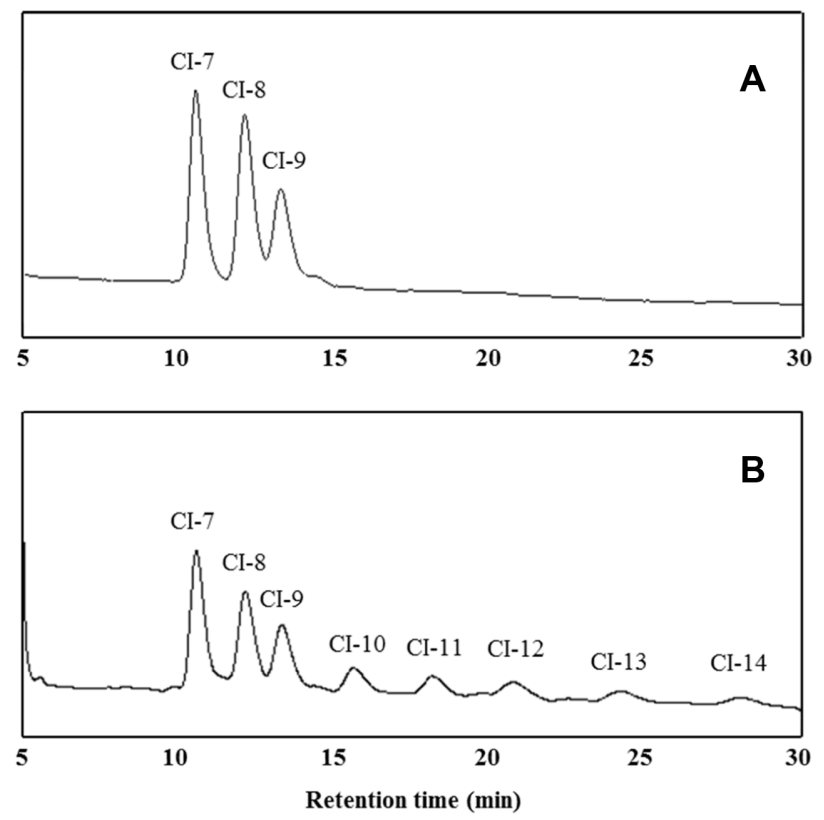

Fig. 4. HPLC analysis of CIs produced by PDCITase.

PDCITase was incubated in $40 \mathrm{mM}$ Britton-Robinson buffer ( $\mathrm{pH}$ 8.0) with $2 \%(\mathrm{w} / \mathrm{v})$ dextran $\mathrm{T} 2000$ at $30^{\circ} \mathrm{C}$ for $2 \mathrm{~h}$, and the enzymatic reaction was stopped by boiling for $10 \mathrm{~min}$. The reaction mixture was treated with DexB and SusB to digest linear oligosaccharides and the remaining dextran to glucose. The produced CIs were quantified on a TSKgel Amide-80 column by a previously described method [3]. A, CI standards; B, PDCITase with dextran T2000. Standard CIs (CI-7, CI-8, or CI-9) were kindly provided by Professor Funane Kazumi. 


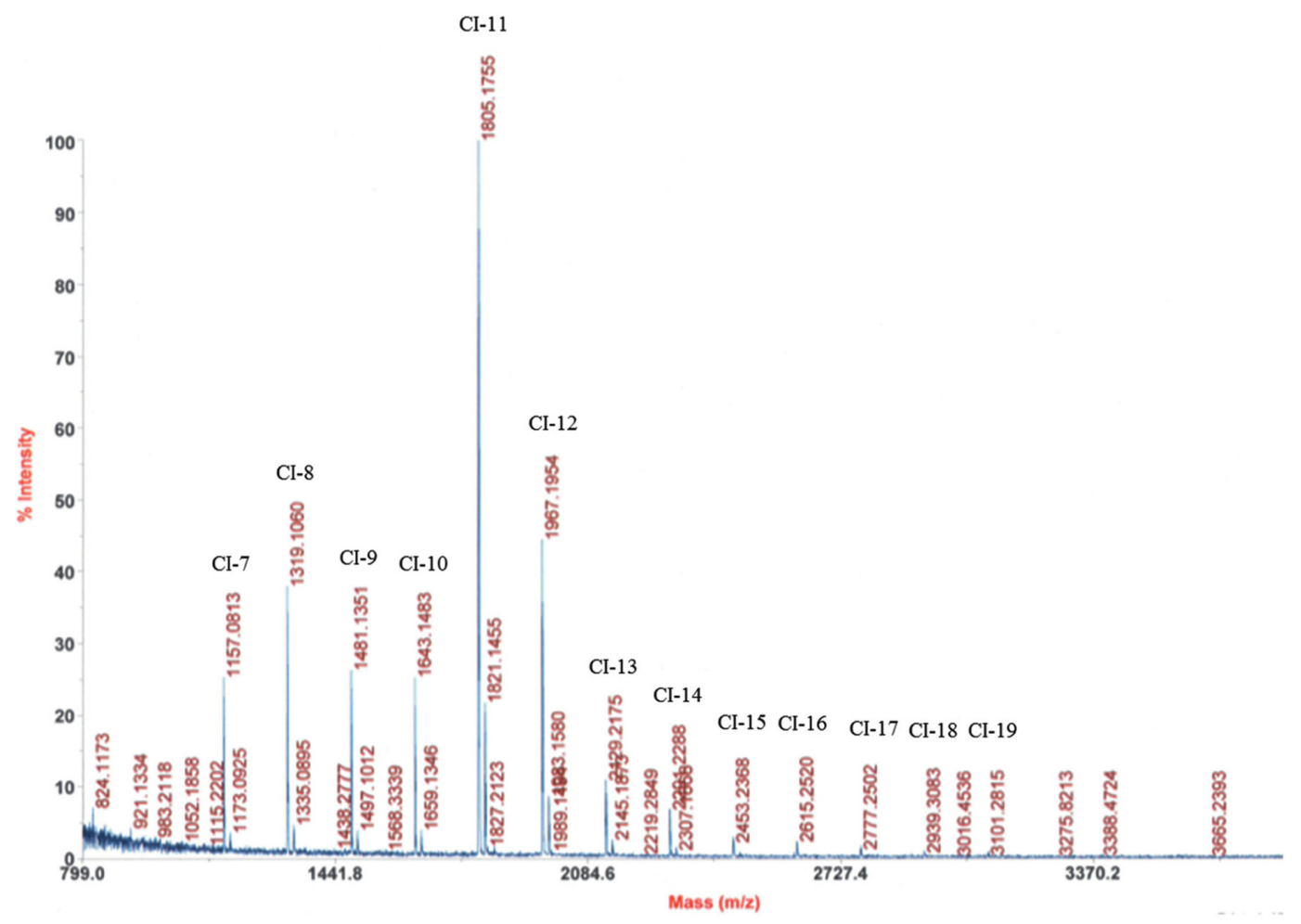

Fig. 5. A MALDI-TOF/TOF MS spectrum of CIs produced by PDCITase.

CITase-T3040 mainly produces CI-8 [18], whereas CITase598K and CITase-U155 mainly produce CI-7 [5]. The amino acid sequence domains of CITase-T3040 were identified as the N-terminal Conserved Region (Ser1-Gly403), CITaseSpecific Insertion (R1, Tyr404-Tyr492), C-terminal Conserved Region (R2, Glu493-Ser596), C-terminal Conserved Region (R3, Gly597-Met700), and C-terminal Variable Region (R4, Lys701-Ser934) [18]. It has been reported that the presence of R1 contributes to the preference for CI-8 production [5]. It is believed that this product pattern is related to the amino acid similarity of the R1 region. In a comparison of the R1 sequence similarities, PDCITase showed 59\% similarity with CITase-T3040. By contrast, PDCITase is $89 \%$ similar to CITase-derived CITase-598K. These results indicated that PDCITase shares greater similarities with CITase-598K, including CI production patterns and a high amino acid similarity (over $80 \%$ ). Nonetheless, PDCITase has high optimum $\mathrm{pH}$ and $\mathrm{pH}$ stability under alkaline conditions. The amino acid sequence differences between PDCITase and CITase-598K involve the R1 region, which contributes to the production of large CIs (from CI-18 to CI19) under alkaline conditions.

In conclusion, the previously uncharacterized PDCITase from $P$. daejeonensis was expressed in an E. coli system and its biochemical properties were characterized. CITase exerts CITase activity toward dextran T2000 in a broad $\mathrm{pH}$ range and produces relatively large CIs: from CI-7 to CI-19. Regarding CIs, this study is the first to report CI-18 and CI19. The high activity at relatively high $\mathrm{pH}$ and broad ranged $\mathrm{pH}$ stability suggest that this enzyme may be useful in the industrial production of CIs at high $\mathrm{pH}$ area without contaminating bacteria. Furthermore, directed evolution experiments aimed at increasing the thermostability of PDCITase are currently underway with the goal of maximizing the utility of the enzyme for CI production.

\section{Acknowledgments}

This research was supported by a grant from Chonnam National University in 2015 and by the Basic Science Research Program through the National Research Foundation of Korea (NRF) funded by the Ministry of Education (NRF2015R1D1A1A01058227).

\section{Conflict of Interest}

The authors have no financial conflicts of interest to declare. 


\section{References}

1. Oguma T, Horiuchi T, Kobayashi M. 1993. Novel cyclic dextrins, cycloisomaltooligosaccharides, from Bacillus sp. T3040 culture. Biosci. Biotechnol. Biochem. 57: 1225-1227.

2. Funane K, Terasawa K, Mizuno Y, Ono H, Miyagi T, Gibu S, Tokashiki $\mathrm{T}$, et al. A novel cyclic isomaltooligosaccharide (cycloisomaltodecaose, CI-10) produced by Bacillus circulans T-3040 displays remarkable inclusion ability compared with cyclodextrins. J. Biotechnol. 130: 188-192.

3. Funane K, Terasawa K, Mizuno Y, Ono H, Gibu S, Tokashiki T, et al. 2008. Isolation of Bacillus and Paenibacillus bacterial strains that produce large molecules of cyclic isomaltooligosaccharides. Biosci. Biotechnol. Biochem. 72: 32773280.

4. Kobayashi M, Funane K, Oguma T. 1995. Inhibition of dextran and mutan synthesis by cycloisomaltooligosaccharides. Biosci. Biotechnol. Biochem. 59: 1861-1865.

5. Suzuki R, Terasawa K, Kimura K, Fujimoto Z, Momma M, Kobayashi M, et al. 2012. Biochemical characterization of a novel cycloisomaltooligosaccharide glucanotransferase from Paenibacillus sp. 598K. Biochem. Biophys. Acta 1824: 919-924.

6. Oguma T, Tobe K, Kobayashi M. 1994. Purification and properties of a novel enzyme from Bacillus spp. T-3040, which catalyzes the conversion of dextran to cyclic isomaltooligosaccharides. FEBS Lett. 345: 135-138.

7. Oguma T, Kitao S, Kobayashi M. 2014. Purification and characterization of cycloisomalto-oligosaccharide glucanotransferase and cloning of cit from Bacillus circulans U-155. J. Appl. Glycosci. 61: 93-98.

8. Funane $\mathrm{K}$, Ichinose $\mathrm{H}$, Araki M, Suzuki R, Kimura K, Fujimoto Z, et al. 2014. Evidence for cycloisomaltooligosaccharide production from starch by Bacillus circulans T-3040. Appl. Microbiol. Biotechnol. 98: 3947-3954.

9. Ichinose H, Suzuki R, Miyazaki T, Kimura K, Momma M, Suzuki N, et al. 2017. Paenibacillus sp. 598K 6- $\alpha-$ glucosyltransferase is essential for cycloisomaltooligosaccharides synthesis from $\alpha-(1-4)$-glucan. Appl. Microbiol. Biotechnol. 101: 4115-4128.
10. Bradford MM. 1976. A rapid and sensitive method for the quantitation of microgram quantities of protein utilizing the principle of protein-dye binding. Anal. Biochem. 72: 248-254.

11. Saburi W, Mori H, Saito S, Okuyama M, Kimura A. 2006. Structural elements in dextran glucosidase responsible for high specificity to long chain substrate. Biosci. Biotechnol. Biochem. 1764: 688-698.

12. Kitamura M, Okuyama M, Tanzawa F, Mori H, Kitago Y, Watanabe N, et al. 2008. Structural and functional analysis of a glycoside hydrolase family 97 enzyme from Bacteroides thetaiotaomicron. J. Biol. Chem. 283: 36328-36337.

13. Britton HTK, Robinson RA. 1931. Universal buffer solutions and the dissociation constant of veronal. J. Chem. Soc 31: 1456-1462.

14. Kim YM, Kimura A, Kim D. 2011. Novel quantitative method for the degree of branching in dextran. Food Sci. Biotechnol. 20: $537-541$.

15. Juhasz P, Roskey MT, Smirnov IP, Haff LA, Vestal ML, Martin SA. 1996. Applications of delayed extraction matrixassisted laser desorption ionization time-of-flight mass spectrometry to oligonucleotide analysis. Anal. Chem. 68: 941-946.

16. Henrissat B, Davies G. 1997. Structural and sequence-based classification of glycoside hydrolases. Curr. Opin. Struct. Biol. 7: 637-644.

17. Lee JS, Lee KC, Chang YH, Hong SG, Oh HW, Pyun YR, et al. 2002. Paenibacillus daejeonensis sp. Nov., a novel alkaliphilic bacterium from soil. Int. J. Syst. Evol Microbiol. 52: 2107-2111.

18. Funane K, Kawabata Y, Suzuki R, Kim YM, Kang HK, Fujimoto Z, et al. 2011. Deletion analysis of the C-terminal region of cycloisomaltooligosaccahride glucanotransferase from Bacillus circulans T-3040. Biochim. Biophys. Acta 1814: 428-434.

19. Suzuki N, Fujimoto Z, Kim YM, Momma M, Kishine N, Suzuki R, et al. 2012. Structural elucidation of the cyclization mechanism of $\alpha-1,6$-glucan by Bacillus circulans T-3040 cycloisomaltooligosaccharide glucanotransferase. J. Biol. Chem. 289: 12040-12051. 